\title{
Short-term Exposure to Household Air Pollution and Risk of Hypertension Among Adults: A Pilot Study in Ibadan
}

\author{
Abiodun Moshood Adeoye ${ }^{1, ~ *}$, Adekunle Fakunle ${ }^{1,2,,^{*}, \text { Olajumoke Aderonmu}^{1} \text {, Bamidele Tayo }}{ }^{3}$ \\ ${ }^{1}$ Department of Medicine, College of Medicine, University of Ibadan/University College Hospital, Ibadan, Nigeria \\ ${ }^{2}$ Department of Occupational and Environmental Health, School of Public Health, University of KwaZulu-Natal, Durban, South Africa \\ ${ }^{3}$ Department of Public Health Sciences, Parkinson School of Health Sciences and Public Health, Loyola University, Chicago, USA
}

Email address:

adeoyemoshood@yahoo.com (A. M. Adeoye), fakunz@yahoo.com (A. Fakunle)

*Corresponding author

\section{To cite this article:}

Abiodun Moshood Adeoye, Adekunle Fakunle, Olajumoke Aderonmu, Bamidele Tayo. Short-term Exposure to Household Air Pollution and Risk of Hypertension Among Adults: A Pilot Study in Ibadan. Journal of Health and Environmental Research. Vol. 6, No. 2, 2020, pp. $37-43$. doi: $10.11648 /$ j.jher.20200602.12

Received: May 11, 2020; Accepted: May 28, 2020; Published: June 4, 2020

\begin{abstract}
Air pollution has been associated with elevated blood pressure in adults. Data on this association in Nigeria, with the highest level of pollution in Africa is sparse. The present study investigated the association between short-term exposure to particulate matter air pollution and hypertension. We conducted a case-control study comprising of 25 adults with hypertension and 25 age-, sex- and geographical location-matched normotensive controls. All participants had 24-hr ambulatory blood pressure (BP) monitoring at the same time as indoor particulate matter monitoring using a real-time particle counter and compared with the WHO guideline limit $\left(25 \mu \mathrm{g} / \mathrm{m}^{3}\right)$. All monitoring was carried out over 24 hours during the wet season. Adjusted odds ratio with $95 \%$ confidence interval for the relationship between hypertension and particulate matter exposure was assessed at $\mathrm{P}<0.05$ using unconditional logistic regression model. Mean indoor $\mathrm{PM}_{2.5}$ and $\mathrm{PM}_{10}$ were significantly higher among hypertensive patients $(33.68 \pm 14.05 \mu \mathrm{g} / \mathrm{m} 3 ; \quad 45.17 \pm 19.53 \mu \mathrm{g} / \mathrm{m} 3)$ compared to normotensives $(17.86 \pm 9.50 \mu \mathrm{g} / \mathrm{m} 3$; $22.45 \pm 11.51 \mu \mathrm{g} / \mathrm{m} 3), \mathrm{p}<0.05$. We observed strong correlations between $\mathrm{PM}_{2.5} / \mathrm{PM}_{10}$ and clinic $\mathrm{BP}(\mathrm{rs}=0.47, \mathrm{p}<0.001 / \mathrm{rs}=0.46$, $\mathrm{p}<0.001)$, day-time $\mathrm{BP}(\mathrm{rs}=0.59, \mathrm{p}<0.001 / \mathrm{rs}=0.62, \mathrm{p}<0.001)$, night-time $\mathrm{BP}(\mathrm{rs}=0.64, \mathrm{p}<0.001 / \mathrm{rs}=0.67, \mathrm{p}<0.001)$ and $\mathrm{BP}$ dipping $(\mathrm{rs}=0.31, \mathrm{p}<0.05 / \mathrm{rs}=0.29, \mathrm{p}<0.05)$. Household size $>5$ persons (aOR: 9.37; CI: $1.37-63.95)$ and $\mathrm{PM}_{2.5}>25 \mu \mathrm{g} / \mathrm{m}^{3}$ (aOR: 5.76; CI: 1.08 - 30.88) significantly increased the odds of hypertension. Short-term exposure to ambient PM air pollution was associated with a higher risk of hypertension. Air pollution reduction strategies may as well help in the prevention and control of hypertension. A large longitudinal study is needed to confirm these findings.
\end{abstract}

Keywords: Household Air Pollution, Particulate Matter, Hypertension, Adults, Ibadan

\section{Introduction}

Cardiovascular disease is one of the leading causes of death worldwide, responsible for about 17.8 million global deaths in 2017 according to the latest estimates of the Global Burden of Disease Study [1]. Hypertension is one of the most common risk factors for cardiovascular disease because of its high prevalence and concomitant cardiovascular risks [2]. The etiology of hypertension is a complex phenomenon and its development involves interaction between various factors, such as genetics, lifestyle, and environmental factors in which air pollution plays a major role [3]. Despite the progress recorded in both the prevention and the management of individuals with hypertension, suboptimal BP remains the single, most important contributor to the global burden of cardiovascular diseases $[4,5]$.

In recent years, there has been a growing appreciation of the role of household air pollution in health outcomes, especially with respiratory and cardiovascular diseases (CVD). The World Health Organization reports that in 2012 around 7 million people died with one in eight of total global deaths resulting from air pollution exposure [6]. This finding more than doubles previous estimates and confirms that air pollution is now the world's largest single environmental health risk [6]. Unlike in other parts of the world where the 
proportion of households mainly relying on solid fuels has declined over the past three decades, it increased up to $77 \%$ in sub-Saharan Africa [7]. The absolute number of people still exposed to smoke from burning of solid fuels almost doubled from 333 million to 646 million. Thus, sub-Saharan Africa is the region with the highest burden of Household Air Pollution (HAP) [7]. Almost 4 million deaths per year are attributable to HAP due to childhood respiratory infection, and chronic lung disease, lung cancer, and cardiovascular disease. Increased risk of raised arterial blood pressure and hypertension, linked to exposure to concentrations of air pollutants, has been documented increasingly in recent years [8].

A randomized control trial carried out among pregnant women in Ibadan, Nigeria also suggested that lowering HAP exposure through the use of cleaner fuel and improved cookstoves might lead to a lower risk of CVD [9]. Human experiments [3] and observational studies [10] suggest that ambient air pollution exposure could raise systolic BP (SBP) and diastolic BP (DBP), although other studies failed to replicate these findings [11]. A few studies have reported a significant association between exposure to fine and coarse particles from indoor environment and self-reported hypertension (RR, 1.22; 95\% CI, 1.08-1.37) but not with measured hypertension $[12,13]$. Brooks et. al had developed the concept of "environmental hypertensionology" to gain insights into the relationship between home ambient air pollutants and risk of hypertension [10]. While this has gained global attention, low resource countries with a high burden of hypertension and air pollution lack data on the subject. This may not be unconnected to poor funding and acceptability of similar studies in African continents whereby culture people advocate privacy and may not allow "strangers" into their inner rooms to measure air particulate. Also certain inconveniences associated with the introduction of $24 \mathrm{hr}$ ambulatory blood pressure measurements may be another hindrance to the smooth running of the study.

Therefore, this pilot study is to assess the feasibility of a large-scale study in our environment to investigate the association between exposure to particulate matter air pollution within the indoor environment and pattern of office and 24-hours ambulatory blood pressure phenotypes.

\section{Materials and Methods}

\subsection{Study Design}

A case-control study design was employed to investigate the association between household air pollution and risk of hypertension among adults in Ibadan. Nigeria. Recruited hypertension cases were matched to suitable controls based on age $( \pm 5)$, sex, and geographical location.

\subsection{Study Location and Population}

This study took place in Ibadan. Ibadan historically acknowledged as the largest city in sub-Saharan Africa. The city is among West African cities that are increasing by more than 100,000 inhabitants annually, a reflection of the combined effects of natural increase and net migration. The 2006 National Population Census estimated the metropolis to be inhabited by 1.34 million people while the total population of Greater Ibadan was 2.949 million. The principal inhabitants of the city are the Yorubas. The city is situated at an altitude ranging from 152 to 213 meters above sea level in a tropical rain forest. The wet season of the year runs from June through October (though occasional showers occur as early as March). In the wet season, temperature ranges from $21^{\circ} \mathrm{C}$ to $31^{\circ} \mathrm{C}$, rainfall from $8.4 \mathrm{~cm}$ to $18.8 \mathrm{~cm}$, and humidity from $54 \%$ to $77 \%$. In the dry season temperature ranges from $20^{\circ} \mathrm{C}$ to $31^{\circ} \mathrm{C}$, rainfall from $1 \mathrm{~cm}$ to $4.4 \mathrm{~cm}$, and humidity from $43 \%$ to $83 \%$ [14].

This study was carried out among individuals greater than 18 years of age who presented with hypertension at the outpatient clinic of the University College Hospital, Ibadan, and individuals without hypertension living in the same geographical areas with the hypertensive patients. A case of hypertension was defined as a systolic/diastolic blood pressure above $140 / 90 \mathrm{mmHg}$ respectively measured at an upright sitting position.

\subsection{Sampling Procedure and Recruitment}

Being a pilot study, we recruited 25 individuals who presented with hypertension at the weekly outpatient clinic of the University College Hospital, Ibadan. Upon arrival at the clinic, the clinical blood pressure was measured after 5 min of rest. Eligible subjects were recruited after the purpose of the study had been explained in English or Yoruba using a consent form. Normotensive subjects were primarily recruited from the same community where the case resides. For every case of hypertension recruited from the hospitals and followed home for indoor assessment, an age and sex-matched controls within the same community as the case was identified by a cardiologist and confirmed to have a blood pressure below $140 / 90 \mathrm{mmHg}$. Once an eligible control is identified, the consent form is immediately administered detailing the purpose of the study before recruitment.

\subsection{Sample Size Power Estimation}

The sample size for the main study would be calculated using the formula:

$$
\mathrm{N}=(\mathrm{r}+1 / \mathrm{r})\left[(\overline{\mathrm{P}})(1-\overline{\mathrm{P}})\left(\mathrm{Z}_{\beta}+\mathrm{Z}_{\alpha / 2}\right)^{2} /\left(\mathrm{P}_{1}-\mathrm{P}_{2}\right)^{2}\right]
$$

where:

$$
\begin{aligned}
& \mathrm{Z}_{\beta}=0.84 \\
& \mathrm{Z}_{\alpha / 2}=1.96
\end{aligned}
$$

$\mathrm{Z}_{\alpha / 2}=1.96$

$\mathrm{r}=1$ (equal number of cases and controls)

$\mathrm{P}_{2}=$ Proportion exposed in the control group $=33 \%$ [15]

$\mathrm{P}_{1}=$ Proportion of cases exposed

$$
\begin{gathered}
\mathrm{P}_{1}=\left[\mathrm{OR}\left(\mathrm{P}_{2}\right) / \mathrm{P}_{2}(\mathrm{OR}-1)+1\right] \\
\overline{\mathrm{P}}=\text { Average proportion exposed }=\left(\mathrm{P}_{1}+\mathrm{P}_{2}\right) / 2
\end{gathered}
$$

Therefore, $\mathrm{N}=480$ (240 hypertensive subjects and 240 
normotensive controls). $10 \%$ of the sample size was employed for the pilot study $=48$ but $(25$ hypertensive and 25 normotensives) were recruited for this study.

\subsection{Subject Interview and Survey}

Eligible hypertensive and normotensive subjects were interviewed using a structured questionnaire to accrue basic demographic, household environment information, family smoking characteristics, and cooking pattern. The questionnaire was administered by trained interviewers in a language that is most suitable for the subject.

\subsection{Blood Pressure Measurement}

Clinic (office) BP was measured using a standard Omron (HEM711DLX) BP apparatus on the left arm placed at heart level after $5 \mathrm{~min}$ rest and using a cuff of appropriate size with the participant in the sitting position and legs uncrossed. Three BP measurements were obtained with a minimum interval of $1 \mathrm{~min}$ and an average of the last two measurements was used in the present analysis. All the participants had a $24 \mathrm{~h}$ ambulatory BP monitoring done using SpaceLabs ambulatory blood pressure monitoring (ABPM) (SpaceLabs Healthcare, Issaquah, WA, USA) which was placed on the non-dominant arm. Cuff sizes were selected after measuring participants' non - dominant arm circumference. The machine was programmed to read every 20 minutes during the wake period and half-hourly at night. Patients were encouraged to proceed with their routine daily activities and to record daytime napping in the diary provided. The participants return to the center after 24 hours for the reading of the machine. Fifty participants with at least 10 and 5 successful readings at daytime and night time respectively were analyzed for this study. For an ABPM measurement to be considered complete, a participant was required to have at least 10 daytime and 5 night-time SBP and diastolic BP (DBP) measurements.

Hypertension was defined as systolic BP (SBP) $\geq 140$ $\mathrm{mmHg}$ and/or DBP $\geq 90 \mathrm{mmHg}$ or being on antihypertensive treatment. Using clinic/office BP and ABPM, we evaluated three phenotype domains: elevated mean clinic and/or daytime BP, diurnal BP patterns, and a disparity between clinic hypertension and out $^{-}$of-clinic hypertension. Elevated clinic BP was defined as mean clinic $\mathrm{SBP} \geq 140 \mathrm{mmHg}$ or $\mathrm{DBP} \geq 90$ $\mathrm{mmHg}$; elevated daytime $\mathrm{BP}$ as mean daytime $\mathrm{SBP} \geq 135$ $\mathrm{mmHg}$ or $\mathrm{DBP} \geq 85 \mathrm{mmHg}$ and elevated night-time $\mathrm{BP}$ as mean night-time SBP $\geq 120 \mathrm{mmHg}$ or $\mathrm{DBP} \geq 70 \mathrm{mmHg}$ [16]. Diurnal BP patterns included nocturnal hypertension, isolated nocturnal hypertension, and a non-dipping BP pattern. Mismatches between clinical hypertension and out-of-clinic hypertension included white coat hypertension, masked hypertension, and masked isolated nocturnal hypertension.

\subsection{Household Air Pollution Monitoring}

Indoor environmental temperature $\left({ }^{\circ} \mathrm{C}\right)$ and relative humidity $(\mathrm{RH})(\%)$ were monitored in homes of recruited hypertensive and normotensive subjects using EXTECH datalogger model 42270. The datalogger was installed in the home of cases and controls over 24 hours and the readings were retrieved using TRLog software version 4.0. The concentrations of indoor particulate matter size $2.5 \mu \mathrm{m}$ and $10.0 \mu \mathrm{m}$ were measured using real-time particle counter model x2132. Measurements were obtained from the kitchen, bedroom, sitting room, and the outdoor environment. All measurements were carried out during the wet season from July - October, 2019. Besides, household characteristics were assessed among participants including types of building occupied by household, household size described as the total number of individuals $\geq 18$ years, the number of rooms in the building, and cooking fuel type.

\subsection{Statistical Analysis}

Analyses were conducted using SPSS software version 22 (IBM SPSS Statistics). Descriptive statistics (proportion, mean, standard deviation, and frequency tables) were used to summarize the data. Inferential statistics such as the chi-square were used to test for the association between subject status and housing condition. Fuel type used was categorized into improved (Gas/LPG and electricity) and unimproved (kerosene, firewood, and charcoal). Means with their standard deviation of $\mathrm{PM}_{2.5} / \mathrm{PM}_{10}$ were determined using independent sample t-test. Pearson correlation analysis was used to test the relationship between levels of exposure and $\mathrm{ABP}$ patterns. Multiple logistic regression was used to estimate adjusted odds ratio (aOR) and 95\% confidence interval $(95 \% \mathrm{CI})$ of hypertension risk by household characteristics and particulate matter exposure.

\subsection{Ethical Consideration}

This study was approved by the University of Ibadan/University College Hospital Ethics Committee. A consent form that detailed the purpose of the research, describes the risks and discomforts involved, the expected benefits of the research, explains how confidentiality will be preserved and how the consent will be documented, was administered to each participant. It also serves to assure the participants that should they decline to perform any or all aspects of the study requirements that they will not be penalized in any way. All information and data were held with strict confidentiality and stored on a password-protected computer.

\section{Results}

\subsection{Participants Socio-demographic and Clinical Characteristics}

Table 1 presents the sociodemographic and clinical characteristics of the study participants. Majority of participants were between $51-60$ years of age with comparable mean age among hypertensives $(52.92 \pm 6.04$ years $)$ and normotensives ( $50.84 \pm 6.41$ years). Female preponderance was recorded among hypertensives and normotensives $(64.0 \%$ and $68.8 \%$ ). A significant relationship was observed between average monthly income and hypertensive status $(p<0.001)$. 
All hypertensive subjects were on anti-hypertensive medication.

Compared to healthy controls, the mean clinic systolic and diastolic BP were higher among the hypertensive participants $(147.60 \pm 29.19 \mathrm{mmHg} \quad$ vs $111.71 \pm 11.03 \mathrm{mmHg}$; $96.50 \pm 17.18 \mathrm{mmHg}$ vs77.14 $\pm 8.52 \mathrm{mmHg} ; \mathrm{p}=0.001)$. Similarly, the mean nighttime diastolic and systolic BP were significantly higher among hypertensive subjects $(126.95 \pm 17.92 \mathrm{mmHg} ; \quad 76.87 \pm 9.27 \mathrm{mmHg}) \quad$ than normotensives $\quad(103.75 \pm 7.76 \mathrm{mmHg} ; \quad 63.00 \pm 5.85 \mathrm{mmHg})$ $\mathrm{p}=0.001$.

\subsection{Housing Characteristics}

In terms of building type, majority (32.0\%) of hypertensives adults reside in mini-flat while a large proportion $(64.0 \%)$ of normotensives resides in a bungalow. A significant association was therefore observed between the type of building inhabited and hypertensive status. More hypertensives versus normotensives $(36.0 \%$ vs $8.0 \%$; $\mathrm{p}=0.01)$ reported a household size of between $6-8$ persons $(\mathrm{p}<0.05)$. A large proportion of hypertensives $16(64.0 \%)$ than normotensives $6(24.0 \%)$ use unimproved stoves $(\mathrm{p}<0.05)$ (table 2).

\subsection{Ambient Particulate Matter Concentrations in Homes of Participants}

The result also showed that the concentration of indoor PM2.5 and PM10 in houses of hypertensive subjects $\left(33.68 \pm 14.05 \mu \mathrm{g} / \mathrm{m}^{3}\right.$ and $\left.45.18 \pm 19.53 \mu \mathrm{g} / \mathrm{m}^{3}\right)$ was significantly higher than values obtained in homes of normotensives subjects $\left(17.86 \pm 9.50 \mu \mathrm{g} / \mathrm{m}^{3}\right.$ and $\left.22.45 \pm 11.51 \mu \mathrm{g} / \mathrm{m}^{3}\right) ; \mathrm{p}=0.02$ and the WHO guideline limit of $25.0 \mu \mathrm{g} / \mathrm{m}^{3}$ and $50.0 \mu \mathrm{g} / \mathrm{m}^{3}$ respectively (figure 1). Houses that use unimproved cooking fuel had higher mean indoor $\mathrm{PM}_{2.5}$ and $\mathrm{PM}_{10}(32.82 \pm 14.80$ $\mu \mathrm{g} / \mathrm{m}^{3}$ and $\left.43.46 \pm 19.94 \mu \mathrm{g} / \mathrm{m}^{3}\right)$ than houses that use improved cooking fuel type $\left(21.38 \pm 12.44 \mu \mathrm{g} / \mathrm{m}^{3}\right.$ and $28.02 \pm 17.18$ $\left.\mu \mathrm{g} / \mathrm{m}^{3}\right), \mathrm{p}<0.05$.

Table 1. Participants Socio-demographic and clinical characteristics.

\begin{tabular}{|c|c|c|c|c|}
\hline Characteristic & Sub-variable & HTN (\%) & NTN (\%) & p-value \\
\hline \multirow{3}{*}{ Age } & $41-50$ & $9(36.0 \%)$ & $9(36.0 \%)$ & \multirow{3}{*}{0.830 .64} \\
\hline & $51-60$ & $14(46.0 \%)$ & $15(60.0 \%)$ & \\
\hline & $61-70$ & $2(8.0 \%)$ & $1(4.0 \%)$ & \\
\hline \multirow{2}{*}{ Gender } & Male & $9(36.0 \%)$ & $8(32.0 \%)$ & \multirow{2}{*}{0.76} \\
\hline & female & $16(64.0 \%)$ & $17(68.8 \%)$ & \\
\hline \multirow{2}{*}{ Ethnicity } & Igbo & $0(0.0 \%)$ & $1(4.0 \%)$ & \multirow{2}{*}{0.30} \\
\hline & Hausa & $0(0.0 \%)$ & $0(0.0 \%)$ & \\
\hline \multirow{2}{*}{ Religion } & Christianity & $17(68.0 \%)$ & $10(72.0 \%)$ & \multirow{3}{*}{0.75} \\
\hline & Islam & $8(32.0 \%)$ & $7(28.0 \%)$ & \\
\hline \multirow{4}{*}{ Education } & NFE & $1(4.0 \%)$ & $0(0.0 \%)$ & \\
\hline & Primary & $3(12.0 \%)$ & $0(0.0 \%)$ & \multirow{3}{*}{0.12} \\
\hline & Secondary & $5(20.0 \%)$ & $10(43.5 \%)$ & \\
\hline & Tertiary & $16(64.0 \%)$ & $13(56.5 \%)$ & \\
\hline \multirow{3}{*}{ Residential location } & Rural & $2(8.0 \%)$ & $0(0.0 \%)$ & \multirow{3}{*}{0.11} \\
\hline & Urban & $21(84.0 \%)$ & $25(100.0 \%)$ & \\
\hline & $<20000$ & $22(88.0 \%)$ & $10(41.7 \%)$ & \\
\hline \multirow{3}{*}{ Monthly income } & $20000-51000$ & $1(4.0 \%)$ & $6(25.0 \%)$ & \multirow{3}{*}{$<0.001$} \\
\hline & $50000-10000$ & $1(4.0 \%)$ & $0(0.0 \%)$ & \\
\hline & $>100000$ & $1(4.0 \%)$ & $9(33.3 \%)$ & \\
\hline Smoking & No & $25(100.0 \%)$ & $25(100.0 \%)$ & - \\
\hline Anti-hypertensives & Yes & $25(100.0 \%)$ & & \\
\hline
\end{tabular}

HTN - Hypertensive; NTN - Normotensive; NFE - No formal education.

Table 2. Housing Characteristics of participants.

\begin{tabular}{llll}
\hline Housing Characteristics & Sub-variable & HTN (\%) & NTN (\%) \\
\hline & Face-to-face & $1(4.0 \%)$ & $4(16.0 \%)$ \\
& Mini flat & $8(32.0 \%)$ & $4(16.0 \%)$ \\
Type of building & Bungalow & $5(20.0 \%)$ & $16(64.0 \%)$ \\
& Duplex & $5(20.0 \%)$ & $(4.0 \%)$ \\
& R\&P & $2(8.0 \%)$ & $0(0.0 \%)$ \\
& $\leq 2$ & $1(4.0 \%)$ & $7(28.0 \%)$ \\
Household size & $3-5$ & $13(52.0 \%)$ & $16(64.0 \%)$ \\
& $6-8$ & $9(36.0 \%)$ & $2(8.0 \%)$ \\
& $>8$ & $2(8.0 \%)$ & 0.02 \\
& $\leq 2$ & $8(32.0 \%)$ & $1(4.0 \%)$ \\
Number of rooms & $3-5$ & $16(64.0 \%)$ & $16(64.0 \%)$ \\
& $6-8$ & $1(4.0 \%)$ & $8(32.0 \%)$ \\
\end{tabular}




\begin{tabular}{lllll}
\hline Housing Characteristics & Sub-variable & HTN (\%) & NTN (\%) & p-value \\
\hline \multirow{2}{*}{ Cooking fuel } & Unimproved & $16(64.0 \%)$ & $6(24.0 \%)$ & 0.001 \\
Generator Use & Improved & $9(36.0 \%)$ & $19(76.0 \%)$ & 0.12 \\
\hline
\end{tabular}

HTN - Hypertensive; NTN - Normotensive; R\&P - room and parlor.
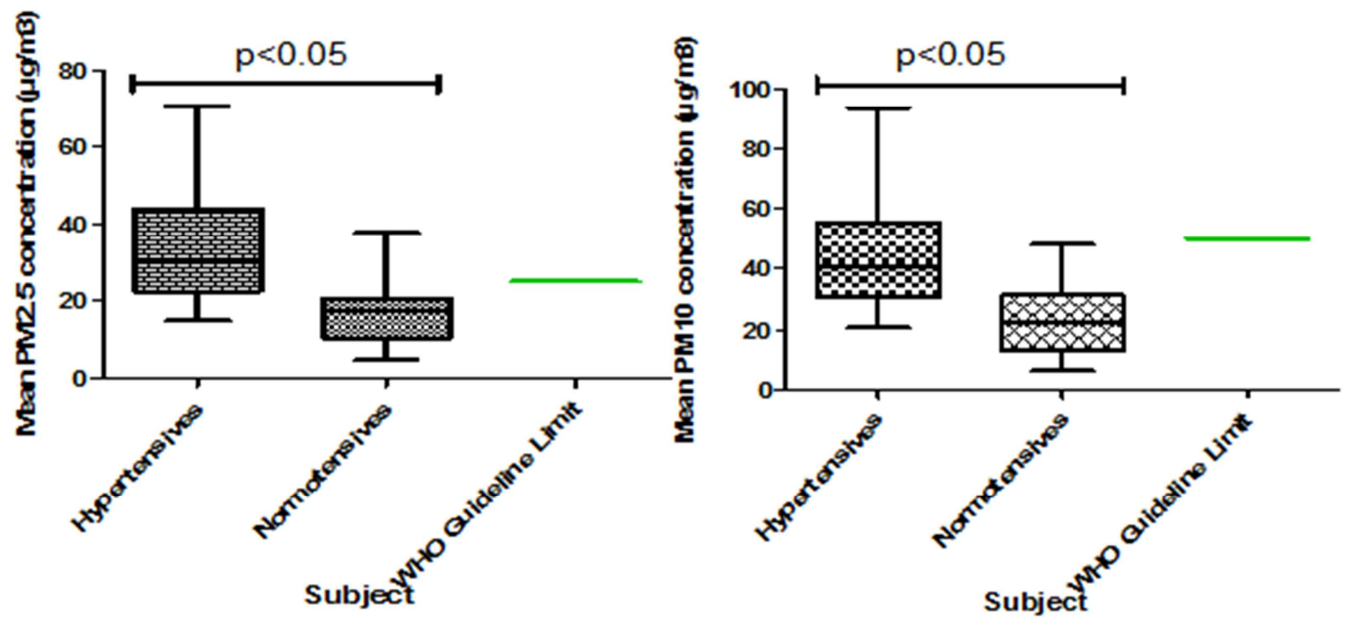

Figure 1. Ambient Particulate matter concentrations in homes of participants.

\subsection{Relationship Between Particulate Matter Concentrations and ABP Measurements}

Table 3 presents the relationship between concentrations of indoor $\mathrm{PM}_{2.5}$ and $\mathrm{PM}_{10}$ and $\mathrm{ABP}$ patterns. Clinic SBP was observed to be moderately correlated with $\mathrm{PM}_{2.5}$ (rho=0.47; $\mathrm{p}<0.05)$ and $\mathrm{PM}_{10}(\mathrm{rho}=0.51 ; \mathrm{p}<0.05)$. Similarly, Day-time ambulatory SBP correlated positively with $\mathrm{PM}_{2.5}(\mathrm{rho}=0.53$; $\mathrm{p}<0.001)$ and $\mathrm{PM}_{10}(\mathrm{rho}=0.57 ; \mathrm{p}<0.001)$. In addition, sleep time SBP and DPB were significantly moderately correlated with indoor $\mathrm{PM}_{2.5}$ and $\mathrm{PM}_{10}$ concentration.

Table 3. Relationship between Particulate matter concentrations and ABP patterns.

\begin{tabular}{|c|c|c|c|c|}
\hline \multirow{2}{*}{ ABP measurements (mmHg) } & \multicolumn{2}{|c|}{$\mathrm{PM}_{2.5}\left(\mu \mathrm{g} / \mathrm{m}^{3}\right)$} & \multicolumn{2}{|c|}{$\mathrm{PM}_{10}\left(\mu \mathrm{g} / \mathrm{m}^{3}\right)$} \\
\hline & Rho & p-value & Rho & p-value \\
\hline Clinic SBP & 0.47 & 0.01 & 0.51 & $<0.001$ \\
\hline Clinic DBP & 0.20 & 0.19 & 0.26 & 0.08 \\
\hline Day-time SBD & 0.53 & $<0.001$ & 0.57 & $<0.001$ \\
\hline Day-time DBP & 0.41 & 0.001 & 0.46 & 0.002 \\
\hline Night-time SBP & 0.53 & $<0.001$ & 0.57 & $<0.001$ \\
\hline Night-time DBP & 0.45 & 0.002 & 0.51 & $<0.001$ \\
\hline
\end{tabular}

\subsection{Adjusted Odds of Hypertension Among Subjects}

Overall, subjects having $>5$ persons living in the same house were 9 times more likely to be hypertensive (aOR: 9.37; CI: 1.37 - 63.95) compared to subjects with less than 5

persons. Besides, subjects exposed to $\mathrm{PM}_{2.5}>25 \mu \mathrm{g} / \mathrm{m}^{3}$ were about 6 times more likely to be hypertensive (aOR: 5.76; CI: $1.08-30.88$ ) than those exposed to $\leq 25 \mu \mathrm{g} / \mathrm{m}^{3}$ (Table 4 ).

Table 4. Predictors of Hypertension.

\begin{tabular}{lll}
\hline \multirow{2}{*}{ Predictor Variable } & Unadjusted & Adjusted \\
\cline { 2 - 3 } & OR (95\% CI) & OOR (95\% CI) \\
\hline Household size; $>5$ persons & $5.63(1.64-19.23)$ & $9.38(1.37-63.95)$ \\
$\mathrm{PM}_{2.5} ;>25 \mu \mathrm{g} / \mathrm{m}^{3}$ & $13.50(3.39-53.68)$ & $5.76(1.08-30.88)$ \\
Number of rooms; $>2$ rooms & $0.09(0.01-0.78)$ & $0.14(0.01-1.59)$ \\
Fuel type; unimproved & $4.63(1.68-19.23)$ & $4.00(0.82-19.61)$ \\
\hline
\end{tabular}

aOR - adjusted odds ratio; $\mathrm{CI}$ - confidence interval.

\section{Discussions}

While hypertension remains a worldwide public health challenge [16, 17] ascertaining the home environment risk factors could provide significant information for the prevention [18]. The key findings of this current study are the 
significant differences in the levels of fine and coarse particulate matter air pollution in homes of hypertensives and normotensives and the contribution of household characteristics and cooking pattern in the burden of particulate matter pollution.

Our study has implicated $\mathrm{PM}_{2.5}$ concentrations within the indoor environment as an independent significant predictor of hypertension among adults in Nigeria. A similar study of 3236 black women selected from the BWHS (Black Women's Health Study) and its extension analysis based on the full cohort $(n=33$ 771) did not find significant associations of $\mathrm{PM}_{2.5}$ exposure with developing hypertension [19, 20]. Interestingly, this current study among black Africans found a significantly higher concentration of both $\mathrm{PM}_{2.5}$ and $\mathrm{PM}_{10}$ in homes of adults with hypertension than homes of normotensive adults. This corroborates the report of a meta-analysis by Cai et al. [21] that investigated the association between short-term and long-term exposure to air pollutants and the development of hypertension among adults. Empirically, particulate matter air pollution is hypothesized to elicit vascular dysfunction through a variety of mechanistic pathways including activation of the autonomic nervous system and increased parasympathetic responses, proinflammatory responses leading to oxidative stress and inflammation, and direct interaction of particles with molecules in blood circulation that regulate endothelial function and cell signaling [22]. While this pathway was not currently studied, abnormal diurnal blood pressure variation has been linked to RAAS pathway, proinflammatory markers, and air pollution [23-25]. This may explain our findings of the significant correlation between ambulatory blood pressure phenotypes and $\mathrm{PM}_{2.5} / \mathrm{PM}_{10}$. Recent evidence further supports that adrenal stress response (e.g, increased glucocorticoids due to hypothalamic-pituitary-adrenal axis activation) may also be involved in particulate matter-induced hypertension [26].

Our study found that $64 \%$ of hypertensive subjects make use of unimproved cooking fuel. This could have resulted from the low household income recorded among majority of hypertensive subjects as compared to normotensives. Similar studies have reported a significant association between household income and cooking fuel type [27, 28]. From this current study, households that make use of unimproved fuel were exposed to an average $\mathrm{PM}_{2.5}$ and $\mathrm{PM}_{10}$ of $32.82 \pm 14.80$ $\mu \mathrm{g} / \mathrm{m}^{3}$ and $43.46 \pm 19.94 \mu \mathrm{g} / \mathrm{m}^{3}$ respectively which were higher than the WHO 24-hours threshold limit (WHO 2016). This supports the notion that short - term exposure to air pollution from most cookstoves produced a delayed increase in systolic pressure that was observable within 24 hours. As reviewed elsewhere, a delayed increase is suggestive of biological pathways with slower onset but more persistent actions. A similar study carried out among women in rural areas of china reported that women who use biomass cookstoves in their kitchen have increased blood pressure [29]. Yip et al. [30]. It also found that those using biomass fuel and kerosene were exposed to an average $\mathrm{PM}_{2.5}$ concentration of $107 \mu \mathrm{g} / \mathrm{m}^{3}$.

There are several strengths of the current pilot study. To the best of our knowledge, our study appears to be the first of its kind in Nigeria, a representative of native black-African population to investigate the significance of exposure of household air pollution on ambulatory BP phenotypes among hypertensive patients. Also, while many potential participants declined participation due to cultural beliefs earlier alluded to, this study has proved it is feasible in our community to execute studies that aimed at investigating the impact of exposure to household air pollution on the prevalence of cardiovascular events without altering the daily activities of the participants. Furthermore, this study has objectively revealed the level of exposure to indoor air pollution from cooking stoves and fuel which can be investigated in larger populations.

However, there were certain limitations to this current study. The relatively small sample size and cross-sectional nature of the study design make the generalizability of our findings and casual relationship between indoor particulate matter pollution and the development of hypertension among adults difficult. While the use of the 24-hour blood pressure measurement allowed for continuous BP measurement rather than one point BP check, a single 24-hours measure of indoor air particle may not represent the usual concentration. Despite this, our sample size is sufficient for a pilot study and the findings have shown clear feasibility of large-scale longitudinal studies on people with hypertension. Also, our findings compared well with a large cohort study [11]. This pilot study, therefore, provides baseline information which could be strengthened through future investigation among larger population thereby creating a platform to demonstrate a dose-response relationship between exposure to indoor particulate matter pollution and development of hypertension among adults.

\section{Conclusions}

Short-term exposure to indoor particulate matter air pollution was associated with a higher risk of hypertension among adults. Besides, the use of unimproved cooking fuel type contributes to the levels of particulate matter air pollution in indoor environments. Therefore, indoor air pollution source reduction strategies through improved cooking pattern as a prevention measure of hypertension is advocated.

\section{Acknowledgements}

The authors will like to appreciate Mr. Mayowa Olatedun and Mr. Omigbile Olamide for their roles in data collection from the participants. Our appreciation also goes to all the participants for their cooperation in making this study a success.

\section{Conflict of Interest}

The authors declare no conflicts of interest and no funding source.

\section{Authors' Contribution}

Abiodun Adeoye: Conceptualization, Methodology, Investigation, Supervision, Writing - review; Adekunle 
Fakunle: Writing-original draft, Methodology, Data curation, Formal analysis; Olajumoke Aderonmu: Methodology, Data curation, Project administration; Bamidele Tayo: Supervision, Validation, Writing - review. All authors have read and agreed to the published version of the manuscript

\section{References}

[1] Global Burden of Cardiovascular Diseases, C., et al., The Burden of Cardiovascular Diseases Among US States, 1990-2016. JAMA cardiology, 2018. 3 (5): p. 375-389.

[2] Kearney, P. M., et al., Global burden of hypertension: analysis of worldwide data. Lancet, 2005. 365 (9455): p. 217-23.

[3] Brook, R. D., et al., Insights into the Mechanisms and Mediators of the Effects of Air Pollution Exposure on Blood Pressure and Vascular Function in Healthy Humans. 2009. 54 (3): p. 659-667.

[4] Bromfield, S. and P. Muntner, High blood pressure: the leading global burden of disease risk factor and the need for worldwide prevention programs. Current hypertension reports, 2013. 15 (3): p. 134-136.

[5] Mitsnefes, M. M., et al., Can office blood pressure readings predict masked hypertension? Pediatr Nephrol, 2016. 31 (1): p. 163-6.

[6] WHO., W. W. H. O. a. G. S. R. o. V. P. G.

[7] Bonjour, S., et al., Solid fuel use for household cooking: country and regional estimates for 1980-2010. Environ Health Perspect, 2013. 121 (7): p. 784-90.

[8] Chen, S.-Y., et al., Associations between Long-Term Air Pollutant Exposures and Blood Pressure in Elderly Residents of Taipei City: A Cross-Sectional Study. Environmental health perspectives, 2015. 123 (8): p. 779-784.

[9] Olopade, C. O., et al., Effect of a clean stove intervention on inflammatory biomarkers in pregnant women in Ibadan, Nigeria: A randomized controlled study. Environment International, 2017. 98: p. 181-190.

[10] Brook, R. D., A. B. Weder, and S. Rajagopalan, "Environmental hypertensionology" the effects of environmental factors on blood pressure in clinical practice and research. J Clin Hypertens (Greenwich), 2011. 13 (11): p. 836-42.

[11] Madsen, C. and P. Nafstad, Associations between environmental exposure and blood pressure among participants in the Oslo Health Study (HUBRO). Eur J Epidemiol, 2006. 21 (7): p. 485-91.

[12] Fuks, K. B., et al., Long-term exposure to ambient air pollution and traffic noise and incident hypertension in seven cohorts of the European study of cohorts for air pollution effects (ESCAPE). Eur Heart J, 2017. 38 (13): p. 983-990.

[13] Brook, R. D., et al., Extreme Air Pollution Conditions Adversely Affect Blood Pressure and Insulin Resistance: The Air Pollution and Cardiometabolic Disease Study. Hypertension, 2016. 67 (1): p. 77-85.

[14] Fakunle, A. G., et al., Home Assessment of Indoor Microbiome (HAIM) in Relation to Lower Respiratory Tract
Infections among Under-Five Children in Ibadan, Nigeria: The Study Protocol. 2020. 17 (6): p. 1857.

[15] Ajayi, I., et al., Prevalence of hypertension and associated factors among residents of Ibadan-North Local Government Area of Nigeria. 2016. 13 (1): p. 67-75.

[16] Lopez, A. D., et al., Global and regional burden of disease and risk factors, 2001: systematic analysis of population health data. Lancet, 2006. 367 (9524): p. 1747-57.

[17] Awoke, A., et al., Prevalence and associated factors of hypertension among adults in Gondar, Northwest Ethiopia: a community based cross-sectional study. BMC Cardiovascular Disorders, 2012. 12 (1): p. 113.

[18] Kumara, W. A., et al., Prevalence and risk factors for resistant hypertension among hypertensive patients from a developing country. BMC Res Notes, 2013. 6: p. 373.

[19] Coogan, P. F., et al., Air pollution and incidence of hypertension and diabetes mellitus in black women living in Los Angeles. Circulation, 2012. 125 (6): p. 767-72.

[20] Coogan, P. F., et al., Neighborhood and Individual Socioeconomic Status and Asthma Incidence in African American Women. Ethnicity \& disease, 2016. 26 (1): p. 113-122.

[21] Cai, Y., et al., Associations of Short-Term and Long-Term Exposure to Ambient Air Pollutants With Hypertension: A Systematic Review and Meta-Analysis. Hypertension, 2016. 68 (1): p. $62-70$.

[22] Brook, R. D. and S. Rajagopalan, Particulate matter, air pollution, and blood pressure. Journal of the American Society of Hypertension, 2009. 3 (5): p. 332-350.

[23] Peixoto, A. and W. White, Circadian blood pressure: Clinical implications based on the pathophysiology of its variability. Kidney international, 2007. 71: p. 855-60.

[24] Widmer, R. J. and A. Lerman, Endothelial dysfunction and cardiovascular disease. Global cardiology science \& practice, 2014. 2014 (3): p. 291-308.

[25] Dubowsky, S. D., et al., Diabetes, obesity, and hypertension may enhance associations between air pollution and markers of systemic inflammation. Environ Health Perspect, 2006. 114 (7): p. 992-8.

[26] Sun, S., et al., Short-term exposure to air pollution and incidence of stroke in the Women's Health Initiative. Environment International, 2019. 132: p. 105065.

[27] Das, I., P. Jagger, and K. Yeatts, Biomass Cooking Fuels and Health Outcomes for Women in Malawi. EcoHealth, 2017. 14 (1): p. 7-19.

[28] Piddock, K. C., et al., A cross-sectional study of household biomass fuel use among a periurban population in Malawi. Annals of the American Thoracic Society, 2014. 11 (6): p. 915-924.

[29] Young, B. N., et al., Exposure to household air pollution from biomass cookstoves and blood pressure among women in rural Honduras: A cross-sectional study. 2019. 29 (1): p. 130-142.

[30] Yip, F., et al., Assessment of traditional and improved stove use on household air pollution and personal exposures in rural western Kenya. Environment international, 2017. 99: p. 185-191. 